\title{
Biosemiotic Foundations of a Darwinian Approach to Cultural Evolution
}

\author{
CARSTEN HERRMANN-PILLATH \\ Max Weber Centre for Advanced Cultural and Social Studies, University of Erfurt, Germany \\ carsten.herrmann-pillath@uni-erfurt.de
}

Keywords: cultural science, semiotics, cultural evolution, neuroscience, memes

The present paper reflects on the state of evolutionary approaches to culture, which are mostly seen as essential for defining 'cultural science'. They manifest two flaws that still block a productive synthesis between the sciences and the humanities. First, they employ an inflationary generic concept of culture that covers all information that is stored and transmitted nongenetically; this differs from the narrower uses in the humanities that focus on the diversity of cultures and their interactions. Second, they approach culture as observable and measurable 'traits', hence do not develop a precise concept of cultural meaning, which must take account of the fundamental property of reflexivity in human cognition. I propose an alternative view that is grounded in biosemiotic analysis of the brain, and that I relate to Robert Aunger's conception of 'neuromemetics'. I already contributed this idea to the first-stage debates about cultural science after 2008. The current paper adds much analytical detail on the systemic nature of cultural semiosis operating in a selectionist logic of brain dynamics, as theorized early on by F. A. von Hayek. I suggest that the bridge between the sciences and the humanities must be built via new disciplines in the neurosciences, such as cultural neuroscience, which avoids both biological reductionism and a mere analogical deployment of evolutionary diffusion analysis in the new field of cultural science. Semiotics is the overarching paradigm of integration, in the distinct versions of both biosemiotics and physiosemiotics. I suggest combining Peircean biosemiotics with Lotman's concept of the 'semiosphere'. In this context, culture is defined by reflexive operations that occur over internal boundaries of the semiosphere that are constitutive of the identity of the agent as the physical locus of neuromeme evolution.

\section{Introduction}

When cultural science was conceived as a distinct new field at the interface between the humanities and the sciences, one central question was the role of evolutionary methods, in two senses. One was evolutionary economics, motivated by the strong interest in how the media and new technologies shape the creative processes in contemporary culture, especially in the context of cultural industries (Hartley 2021). The other was the direct application of evolutionary theory for analyzing cultural phenomena, which overlaps with the former since we can approach economic activities as elements of a larger cultural canvas. Both movements were intended to transform the study of culture into a'science': What that actually means is still open to debate, but the important elements include quantification, formal modelling, and a focus on technology. However, that claim also triggered much debate, which 
has still not resolved the fundamental question: What is the relationship between 'culture' as used in the sciences, especially biology, and in the humanities?

This is not merely a philosophical quandary but boils down to defining the methods of cultural science: In this paper, I concentrate on one essential point, the use of Darwinian theory in analyzing culture. This has been mostly informed by the seminal contributions of scholars such as Cavalli-Sforza and Feldman (1981) and Boyd and Richerson (1985) and was introduced to the cultural science group by archaeologists and complex systems theorists, who use evolutionary modelling to analyze cultural change. In the 1980s, such ideas were also simultaneously appearing in evolutionary economics (Nelson and Winter 1982, Metcalfe 1998).

In my work, I relied on these new approaches, but added my own distinct perspective grounded in Peircean biosemiotics (Herrmann-Pillath 2010, 2013). When using the term 'Peircean', I mean to indicate that I do not engage in Peirce exegesis, but rather take Peirce as a major inspiration, while also adding insights that diverge from his original contributions (especially on the point of naturalism, similar to Millikan 2009). In this paper, I present a few new ideas. I start out by pondering the problems from a purely Darwinian account of culture, which was masterfully exposed by Alex Mesoudi in his 2011 book Cultural Evolution. Then I present a new model of 'neuromemetics' in relation to the concept of culture as developed by Hartley and Potts (2014), which was first expounded by Robert Aunger (2002). I conclude with an outlook on the relationship between cultural science and the neurosciences.

\section{Pitfalls of Darwinizing Culture}

\section{Broad versus narrow concepts of culture}

The nutshell of Darwinian cultural science is: Transfer of the modelling methods for population genetics to cultural analysis and the recognition of various new forms of information transmission specific to culture, such as learning from model individuals or horizontal transmission; then checking what kind of transmission mechanisms might work in distinct empirical domains, defining your data categories and testing the models. Hence, these approaches hinge on what are regarded as the fundamental units of cultural evolution, and these must be measurable to allow employing quantitative tools. Therefore, most of this research is about 'traits', such as arrowheads used by prehistoric people and dispersed in many variants across a territory, textile production methods or first names given to new-borns. In other words, most Darwinian cultural analysis is about the diffusion of cultural traits that are observable and measurable. This includes more abstract traits, such as values, if these can be objectified by appropriate methods, such as value surveys.

However, this means that, in terms of the biological template, we only deal with the phenotypic level, and not with the genotypic level. This is a problem once we consider the definition of culture that is mostly employed by evolutionary cultural scientists, such as suggested by Mesoudi (2011): 'Culture is information that is acquired from other individuals via social transmission mechanisms such as imitation, teaching, or language'. Is an arrowhead 'information'? In a biological framework, an affirmative response would confuse the genotype and phenotype: Phenotypical traits have functions, but the information is stored and transmitted at the genetic level. As for the arrowhead, we may assign a function to it, but the information on it is a different thing, such as the knowledge of how to make and use it. In other words, most Darwinian evolutionary analysis does not explore population level flows of information, but only the diffusion of traits as cultural phenotypes. Indeed, Mesoudi suggests a long list of alleged embodiments of information, reaching from neurophysiological structures to texts, but without developing a precise definition of '(cultural) information'. This compares with the sophisticated discussion of information in biology, following seminal contributions such as that of Maynard-Smith (2000) (survey in Godfrey-Smith and Sterelny 2018). By ignoring this question, 
Mesoudi avoids a territory filled with landmines, which is the extension of the replicator/interactor duality to the analysis of cultural evolution (Hull, Langman and Glenn 2001). However, this was the key idea in Dawkin's (1989) early proposal to Darwinize culture, motivating the emergence of memetics in the 1980s and 1990s (Aunger 2000), which was then widely perceived as a cul-de-sac (Cannizarro 2016).

Another problem with Mesoudi's definition, also shared by other evolutionary scholars, is that he deploys the generic notion of culture as in biology. This implies that culture is a sort of 'negative'; where all kinds of information that are not transmitted by genes are related to culture, such as the technology, religion, political organization and so on. Although such broad and inclusive definitions can be found throughout anthropology since its inception (Brumann 1999), most humanities scholars approach culture in the plural, just like distinguishing between the generic capacity of languages and the diversity of spoken tongues. Interestingly, this view is also shared by most economists, who tend to treat culture as being separate from domains such as technology or market organization, which exactly motivates their question of how culture impacts on these: Here, culture is in the plural, such as the diverse value stances of different groups and societies (Alesina and Giuliano 2015). In the biological view as championed by Mesoudi, economic evolution is just a special case of cultural evolution.

In the cultural science discourse, there have been efforts to reconcile these two different views, which, however, have further revealed the limitations of the established evolutionary approaches. John Hartley and Jason Potts (2014) approach culture as the medium in which group identities are established, reproduced and communicated. This narrows the reach of culture to a substantial extent, while at the same time providing a Darwinian rationale: Cultural group selection. For example, arrowheads would not be 'culture' as long as their function is only improving hunting technology, and would only become 'culture' if their shape also indicates the group to which the hunter belongs (Rogers and Ehrlich 2008). This narrow definition matches the definition proposed by the economists Beugelsdijk and Maseland (2010): '...we loosely define culture as those behavioural and ideational structures that are deemed essential to the constructed identity of a community'. I have elaborated on that narrow view also in my own work, both systematically (Herrmann-Pillath 2013) and empirically (Herrmann-Pillath 2017).

The great advantage is that we can now investigate the role of cultural contact, clashes and mergers, and how people use culture in expressing and shaping their identities, which is the bread and butter of much anthropological research on culture, and a core concern in the entire discipline of 'cultural studies' (Hartley 2003). Also, we can refer these phenomena to a precise evolutionary rationale, which is enabling cooperation in human groups by means of shared identities (Bowles and Gintis 2011). At the same time, this does not invalidate the evolutionary method when it comes to tracking the diffusion of cultural traits. But we must neatly distinguish between generic non-genetic information and culture since the function of culture is much more specific than assumed in the original approaches to cultural evolution.

\section{The missing link: The brain}

There is another fundamental difference between the scientific approaches and the humanities views: The former assume that researchers can approach culture as an objective fact; that is, a 'datum' for external observers, such as the frequency distribution of the types of arrowheads. There is no need to ask people what the 'datum' means to them, but if that is deemed necessary, then it should only be under the condition that we can employ methods to objectively determine this meaning. Although I present this here as a split between the two Snowian 'cultures', in fact this tension inheres the Mesoudi definition of culture: Most Darwinian cultural theorists do not properly analyze the concept of the 'information' that they take for granted. Especially, they do not explore the semantic dimension of information, which is by no means only confined to the humanities (Floridi 2019) and even has a 
physical interpretation (Kolchinsky and Wolpert 2018). Deciphering this dimension of culture is what the main protagonists of 'thick' cultural hermeneutics in the humanities have in mind (classically, Geertz 1973): In fact, their view makes full sense in a scientific account of 'information'.

The semantics of information lies in its use or interpretation by the receiver of that information: Standard Darwinian analysis simply assumes that in any kind of transmission process, the meaning of information is the same for the sender and receiver, unless there are copying errors, which can be conceived as corresponding to the biological notion of mutation. There is no room for the autonomous and even creative use of information by the receiver. Anyway, there is no clear conception of what the senders and receivers are: This reveals that there is a deep conceptual break between the concept of information in biology and in the human sciences: In biology, information is embodied in a meaningless medium (DNA), whereas in the case of humans, we focus on a special kind of culturally empowered agent as a key processor of information. What is the specific difference? There are approaches in biology that aim at a fusion of both concepts in moving to a higher and more abstract level of systems in which meaning, aka semantic information, is an emergent property that cannot be reduced to the genetic level (for example, Oyama 2001).

The differentia specifica of the humanities, which can be generalized in systemic approaches and thereby reconstructed in biology, is reflexivity - a category that is ominously missing in mechanistic models of cultural evolution. Reflexivity is essential for establishing the human kind of agency and is clearly embodied in evolved neurobiological structures (such as the exceptionally large prefrontal cortex) and is also essential for human acculturation: G. H. Mead (1934) early on presented the basics on this. Reflexivity also defines the difference between 'science' and 'humanities' in the precise sense that in the latter reflexivity is the motor of creativity as an intentional act: The artist reflects on the colours of a leaf and considers new ways to catch and communicate her feelings about it to an audience, which in turn ponders the artwork and the feelings generated by it, thus eventually establishing an artistically mediated relation to the original object. In fact, in some notions of 'objectivity' this kind of reflective act is even seen as a necessary condition for accessing the essence of the real object (Daston and Galison 2010).

Reflexivity also defines the function of culture in fixing and expressing agent identities, in two senses: One is reflexivity of the interactions with others, such as pondering their intentions with reference to ours and moving up reflexive ladders in thinking about what others assume about my thinking about them, and so forth. The other is reflexivity regarding the self, such as reflecting about my intention as an intentional state, and thereby moving across meta-representational levels. Culture as an externalist medium of creating shared understandings, such as most significantly in language, radically reduces the complexity resulting from reflexivity (Ross 2007; Zawidski 2013).

Hence, the most important challenge in establishing cultural science is how we can relate reflexivity and evolutionary concepts and models. This challenge is most salient when we consider the aborted science of memetics, which albeit gone, has left behind a vibrant legacy in the humanities and even in popular culture (Cannizarro 2016, Schlaile 2021). The original idea behind memetics closely followed biology in positing an embodied unit of cultural evolution, the meme, which is as meaningless as the gene (Dawkins 1989). Hence, there is also no room for reflexivity: Memes just reproduce, and they exploit resources that are partly human, such as attention or memory, but also technological, such as communication networks. If memes defined culture, however, the rupture with the humanities would be most radical: Culture would be the domain of non-human memes, which would only piggyback on or even hijack humans, literally as the popular uses have it,'memes going viral'. Culture would neither have a meaning nor a function for humans, and if we diagnose a function, this must be explained in terms of the advantages for meme reproduction, and not for us humans.

This most radical version of memetics did not gain widespread approval, yet I think that it was important to lead the evolutionary logic to its consequence. Indeed, 'soft' cultural evolutionary theory 
just leaves the questions of meaning and function open or deliberately obscure: Culture, cui bono? Indeed, recent approaches to posthumanism in the Anthropocene epoch seem to restate the memetics proposition that technologically mediated culture assumes an autonomous role vis-à-vis the human agent as conventionally understood (Hartley, Ibrus and Ojaamaa 2020).

In my own work, I embarked on a different road, and interestingly Mesoudi also mentions this direction, yet without systematic elaboration. This is the explicit consideration of the role of the brain in cultural evolution. The neglect of the brain is due to the focus of evolutionary analysis on population level traits. But if we strictly implement a distinction between traits and units of trait-generating information, the only place beyond the DNA where this information could be located is the brain (unless we enrich our ontology by supra-individual entities with autonomous capacities for reproducing information: Al?). In the Darwinian analysis of transmission mechanisms, this is only implicitly given, since we must ask what determines the 'choice' of a mechanism by the senders and receivers of cultural information, such as when children listen to parents, and when to their peers. In a strictly naturalistic account, these mechanisms must be conceived as neurophysiologically embodied.

That was also the conclusion drawn by Robert Aunger (2002) in his seminal contribution to memetics in the book The Electric Meme. That title was unfortunate, I think, because it is too catchy, signalling a lack of scientific respectability, and because it failed to clearly identify the conceptual breakthrough: This was the introduction and detailed exposition of the concept of the 'neuromeme'. That is probably the reason why even today followers of memetics regard his approach as just one version of memetics and posit several variants of memes that again do not distinguish neatly between the levels of the replicator and interactor (Schlaile 2021). Aunger's approach dovetails with evolutionary approaches in the neurosciences, with the seminal contribution of Gerald Edelman's (1987) Neural Darwinism. These approaches, though theoretically productive, have been languishing because of the lack of empirical evidence on self-replicating neuronal structures (Fernando, Szathmary and Husbands 2012). At the same time, however, there is a considerable body of literature on evolutionary brain mechanisms in the neurosciences and the cognitive sciences, which tie up with Darwinian thinking in two senses: First, in arguing that the evolutionary mechanisms of determining action are themselves the result of natural selection among alternative ways of action determination (Cisek 2007; Pezzulo and Cisek 2016), and second, that these mechanisms operate in the modes of variation, selection and retention (Hadders-Algra 2018; McDowell 2019) (I survey this literature in Herrmann-Pillath 2021b).

I picked up this line of thinking in my early contribution to the cultural science agenda, which was part of a book series launched by John Hartley (Herrmann-Pillath 2010). Since then, I have further explored its ramifications, with the distinctive twist of employing naturalistic semiotics (HerrmannPillath 2013, 2020, 2021a) as established in biosemiotics and physiosemiotics (Herrmann-Pillath and Salthe 2011). Semiotics establishes the missing link between the population level evolutionary analysis of trait diffusion and the micro-level analysis of information (for a related claim, see Cannizarro 2016). In the next section, I present a new version of my conceptual framework. There are mainly two novelties. First, I add considerable micro-analytical detail, second, I combine my previous focus on Peircean biosemiotics with Lotman's (1990) concept of the 'semiosphere'. Regarding the latter, I hope to contribute an important clarification to the relationship between the semiosphere and culture. Lotman is ambivalent here, even when it comes to positioning his views in the context of cultural Darwinism. In fact, Lotman's various conceptualization of culture come close to Mesoudi's in defining culture as a non-hereditary means of information storage, aka memory and its transmission (Tamm 2019). At the same time, however, Lotman's central notion of 'autocommunication' refers to what I introduced as 'reflexivity' (Andrews 2015). Hence, an important question is: How can we develop a naturalistic account of reflexivity as a semiotic category? Further, Lotman and his followers often seem to conflate culture and the semiosphere (which is even true for John Hartley). Lotman was inspired by Vernadsky in developing the notion of the semiosphere, which suggests an extension beyond the 
human domain, even in the sense of 'physiosemiosis', which is also supported by biosemiotic interpretations of Peircean semiotics (Nöth 2001). However, if at the same time the relationship with culture remains diffuse, would that imply a sort of panpsychism in extending the human phenomenon of culture even to cosmological dimensions (apparently also implied by some versions of biosemiotics, e.g. Hoffmeyer 1996)? I strongly object to this move and hence argue that we must clarify, in Lotman's own terms, the distinction between culture and the semiosphere (Torop 2005). I will argue that this clarification refers to culture as a specific form of semiotic mediation of reflexive autocommunication, or, n-th level autocommunication. In other words, culture is exclusively about the core Lotmanian notion of 'border' or 'boundary', however as created and continuously transformed by reflexive human agency. Culture is quintessentially human, whereas the semiosphere transcends the human domain.

\section{Cultural Evolution:}

\section{The Biosemiotic Alternative to Reductionist Darwinism}

\section{Neuromemes and semiosis}

Let me begin with fixing the fundamentals. I analyze information in terms of the semiotic triad relating object, sign and interpretant, which is informed by modern biosemiotics (e.g. El-Hani et al. 2006) (Figure 1). Biosemiotics offers the King's way to integrate the two 'cultures' of the sciences and the humanities and is a powerful means to clarify the semantics of information in general evolutionary approaches (Salthe 2009). In this brief exposition, I do not discuss the details of Peircean terminology and its various interpretations (Short 2007). While the entire triad is often treated as the 'sign', and the 'sign' in my diagram is represented by the 'sign vehicle', I suggest approaching the triad as a unit of semantic information, and the sign (aka sign vehicle) as the embodied mediator between the object and interpretant (Herrmann-Pillath 2021a). All three elements are physical, in the sense that they do not involve 'mental' mediation (thus strictly avoiding any form of Cartesian dualism). Hence, my semiotic approach is rigorously externalist and naturalistic (in the sense of Papineau 2009): This represents a distinct view in the wider range of semiotic theories, which, perhaps even mostly, would not emphasize the physical nature of the sign (such as in the context of literary studies). In particular, in line with Peirce's pragmatism, the interpretant is an action that is triggered by the sign (which renders my view close to other Darwinian approaches to meaning, such as teleosemantics, Macdonald and Papineau 2006; Millikan 2009).

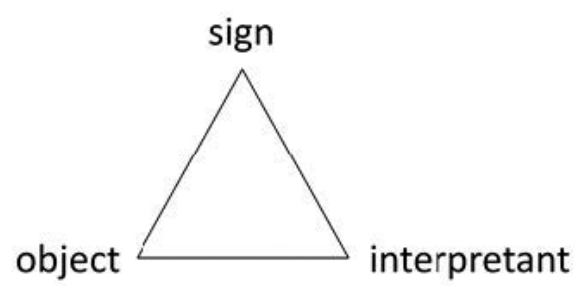

Figure 1. The Peircean triad

For applying this basic framework, it is important to recognize that semiosis is a process that unfolds connections about the manifolds of such basic elements of information (what Salthe 2009 calls a 'system of interpretance'). This means the interpretant becomes an object for another linked semiotic triad. Let me just choose a simple example as a workhorse: Consider the object is an 'apple', and the interpretant is the action 'eat an apple.' This is mediated by the sign 'apple', which is an externalized 
image of an apple, embodied in the object (for psychological evidence on these distinctions, see Ariely and Norton 2009). The information embodied in this process is retrievable if we ask the simple question: 'Why do you eat this object?'. In asking this question, we take the action qua interpretant as another object, and there is further semiotic mediation; for example, relating the observed action to a subsequent action, such as imitating eating an apple, and so forth. In other words, while recognizing the semiotic triad as an elementary unit, the notion of semiosis is necessarily systemic, especially when it comes to the semiotic constitution of the object: In this regard, semiotics evokes a Kantian idea - there is no epistemically accessible 'object an sich', all objects are ultimately constituted as signs mediating the actions in which the objects are entangled. From this, it follows that we cannot reduce semiosis to the triadic unit as such but must conceive it as the evolutionary unfolding of nested and interlocking interpretants:'Meaning'emerges in this process as continuously and creatively transcending single instances of interpretation (Nöth 2002), though potentially converging to a 'final interpretant' (Short 2007). In other words, Salthe's 'system of interpretance' is the link between the biosemiotic micro-level and the Lotmanian macro-level, as represented by the concepts of the triad and the semiosphere, respectively.

I add another dimension in distinguishing between semiotic mediation and the causal mechanism that links an object and interpretant (Herrmann-Pillath 2012) (Figure 2). This is what I call 'bimodality', which can distinguish between different forms of causation (efficient, formal, final; e.g. compare Hulswit 2002). For example, the apple as an object interacts with the interpretant in many ways, such as when light reflected by the apple impacts physically on the eyes and triggers neurophysiological circuits of the visual system, or when we eat the apple, its various chemical composites cause somatic responses, such as changing the acidity in our stomach fluids.
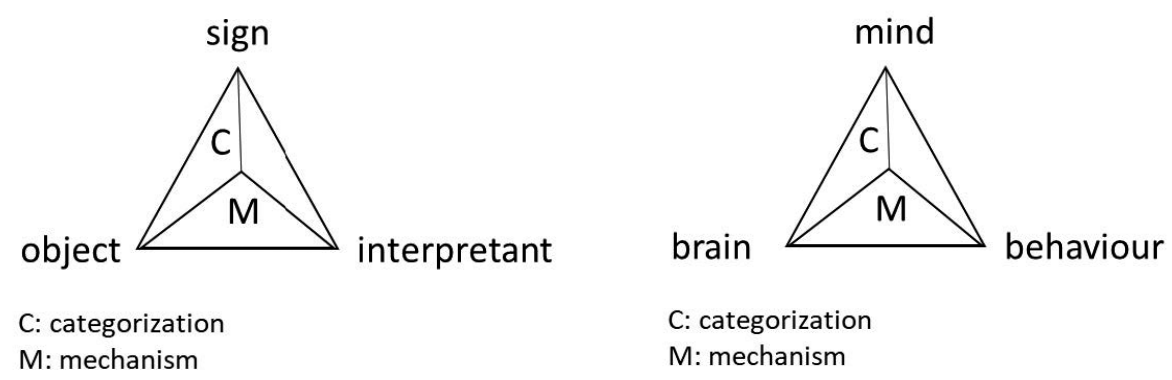

Figure 2. The complete triad (2a: generic form; $2 \mathrm{~b}$ : generic form projected on human action)

Figure $2 \mathrm{~b}$ sets the scene for the subsequent analysis, where the generic conceptual framework of the semiotic triad is projected on human action, with the three fundamental categories of the brain, mind and behaviour. The key point of transition is the distinct form in which the object is treated: As I argue now, objects such as Kantian 'objects an sich' can never be epistemically accessible unless as objects internal to the brain. The world external to the brain is only accessible via the causally induced neurophysiological patterns in the brain (Friston 2010). This creates the infamous problem of'the gap' between causal analysis and the analysis of meaning (Levine 2009), which, I argue, is resolved in the biosemiotic approach. If we only consider the efficient-causal chain ('mechanism'), neurophysiological causal mechanisms generate behaviour, and only these. However, these mechanisms are'meaningless'. Meaning emerges from intermediation by signs, which results in the categorization of mechanisms. This is what is commonly designate as the 'mind' (for a full treatment of these complicated issues, see Deacon 2013). Via semiotic mediation, behaviour is directed by intentions, i.e. it becomes goaldirected (what Deacon calls 'teleodynamic'). The core question then is how these signs come into being, thereby 'minding the brain'. In recent neuroscience research, this has been directly related to 
cultural evolution (Northoff 2016). This is a view that was already developed much earlier by various scholars rooted in the extremely productive early 20th century intellectual climate. I mention two here who have strongly influenced my views (Herrmann-Pillath 2018, 2021 b). G. H. Mead (1932) established social psychology by explicitly applying evolutionary reasoning on the brain as a biological carrier of the mental capacities of humans, yet vigorously rejecting reductionism. F.A. von Hayek (1952) developed an evolutionary theory of the mind in its relation to the physical structure of the brain. Both thinkers have been somewhat neglected in the current debates on cultural science.

I do not have the space to explore the details fully here, but the bare bones are put together in Figure 3. This presents a unit of semiosis constituted by a 'meta-triad', representing a closed circuit of semiotically mediated causal interactions, thus revealing the systemic nature of semiosis, and formalizing Lotman's notion of autocommunication in terms of triadic analysis. At each junction (IA, EA, NM) between the elementary triads, the interpretant of the respective basic triad is the object of the succeeding triad. The fundamental premise is in line with Hayek's observation that the external world in no way can directly cause complex behaviour in humans, apart from mere physiological responses (such as digesting a toxin and suffering from convulsions). There is a fundamental gap between the brain and the world, and this can only be reduced via internally generated neurobiological processes. This emphasis on the fundamental gap is also central to more recent theories on brain/world relations, such as Maturana and Varela's (1980) theory of brain autopoiesis or Karl Friston's (2010) 'free energy theory of the brain. Hayek's seminal idea was to explain the emergence of the internal representation of the world via neuronal evolution, an idea that was later (and independently) elaborated in much detail by Gerald Edelman and others (e.g. Calvin 1998).

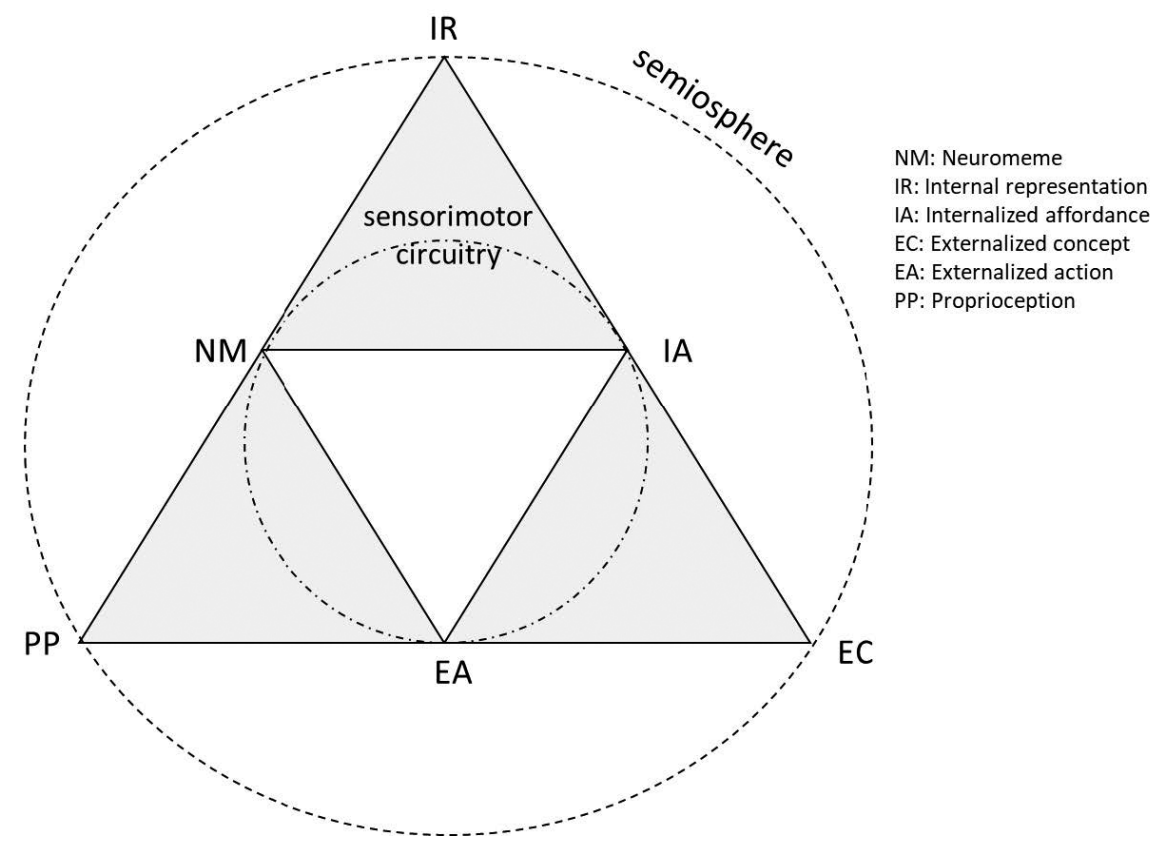

Figure 3. Minding the brain by means of semiosis

In my own work, I suggested taking the'neuromeme'as the basic unit of brain evolution (NM in Figure 3). Following Aunger, this is defined as a self-replicating neurophysiological structure. But how does this structure develop? As shown by Edelman, Friston and others, brain evolution unfolds via complex (i.e. multi-level and recursive) feedback circuits that relate action and action consequences with the neurophysiological structure that caused the action. However, at no point is there a direct impact of the external world on the brain, i.e. an action consequence is just another neurophysiological 
pattern: Even if we ingest a toxin, we only know about it via our feelings, such as caused by convulsions. That means, the process does not manifest a 'correspondence' of the internal brain structures and the world, but a 'coherence' in the sense of approaching an internal equilibrium (Friston 2010; an argument elaborated much earlier by another intellectual giant, Piaget 1975). In other words and conceptual frames, this corresponds to autopoiesis or recursive autocommunication. For understanding this dynamic, we must conceive it as the result of a long process of development, i.e. human ontogeny (Bogdan 2010). The human brain/mind does not operate this way from scratch, but rather it evolves these structures, based on genetically endowed basics. This view is Meads', but was most thoroughly developed by another contemporary, Vygotsky (1934). The internalization and gradual construction of the 'mind' is an essential outcome of brain evolution and explains how the 'world' can be represented in the brain: The world is the accumulated information about our own actions in the world, which emerges from semiosis (which corresponds to Lotman's central notion on memory, see Edwards 2015). This is only possible via being scaffolded by the semiosphere, which bridges the boundary between the inner and outer domains of semiosis.

That means, first, that there is no 'world' beyond the internal representations (IR in Figure 3) of the brain, and second, these representations are not'images' or other units, but rather are neurophysiological patterns. In the diagram, I distinguish between three types of signs: The internal representation IR, the externalized concept EC, and the proprioception of action PP (for more detail, see Herrmann-Pillath 2020). All three relate to action in a principled way; that is, in terms of being physically constituted as sensorimotor circuits. This view was early on developed by Lashley (1951) in his 'common coding' concept (stating that all perception involves the neurophysiological structures of action generation and realization) and has been systematically elaborated in more recent theories on 'grounded cognition' (Barsalou 2009). The central conclusion follows: Manifesting the principle of bimodality, there are two levels upon which the three triads are connected in a circuit, one is the sequence of sensorimotor action generation (the inner circle in Figure 3 ) and the other is the semiotic circuit, the semiosphere, where the signs, however, are also sensorimotor patterns, yet engaging objects beyond the physical boundary of the brain, and there is no separate domain of 'mentalese.' Another concept that looms large here is simulation: Perceiving an apple is a simulation acting on the apple (Hurley 2008), and the simulation is the sign.

My account of enacting action is simple, and again, tripartite: intention, object and action. However, the 'object' in the sense of the external goal of action, such as the apple in the world, is not at the centre; instead the neuromeme that is related to that external object via semiotic mediation is. In other words, the primary objects that the brain is related to are those that are parts of itself: the neuromemes (this is the mechanistic manifestation of Maturana's and Varela's 'autopoiesis'). The first stage of semiosis is about connecting the neuromeme with an interpretant, which is the internalized affordance (IA in Figure 3; following Bogdan 2010). The neuromeme, to emphasize, is 'meaningless', such that, for example, we cannot speak of a neuromeme representing the 'apple'. Instead, the neuromeme is tied to a sign via the interpretant that points to the apple: This is an internal representation that reflects past action patterns that involved actions on apples, and that categorize the various downstream neurophysiological activations originating with the neuromeme. That means, the neuromeme triggers a manifold of possible action pathways (eating the apple, kicking the apple, offering the apple to others and so on), and these are categorized, and hence selected at the first stage, via internal representations that relate the neuromeme with an internalized affordance (in psychology, these manifolds of possible action trajectories have been referred to as 'event files', see Hommel and Wiers 2017). This corresponds to the standard concept of 'intention': 'Internalized affordance' is more accurate because this directly relates the 'intention' to the external object in which the affordance is grounded (matching with Cisek's 2007 evolutionary approach). However, there is no direct relation with that external object an sich, but only to the externalized concept embodied in the object (Ariely 
and Norton 2009) - the internalized affordance. That is, the 'apple', which we semiotically internalized as an external object susceptible to the action of eating occurring, which enables our formation of the intention to eat.

In the next step, the action (EA in Figure 3) is what interprets the internalized affordance. Most importantly, this includes the possibility of failure, i.e. taking the wrong type of action (much emphasized in teleosemantics, Neander 2006) (we do not eat the apple, but instead throw it at our partner). This is the only point where the world 'out there' comes into play: Although we have no direct epistemic access to the world, our actions meet the world and produce real consequences. However, and again, we cannot directly access these consequences epistemically, only in terms of sensorimotor representations in the brain. As G. H. Mead emphasized early on, this is where proprioception comes into play, which is about perceiving one's own action and its consequences (for a modern and advanced approach on that, see Friston 2010). Now the circle is closed, as the interpretant of the action is the neuromeme, in the sense that what counts is the selective stabilization of its recurrent pattern, caused by proprioception. In a metaphorical way, we may interpret the neuromeme as a trigger that switches on a neurophysiological circuitry, which eventually feeds back to the trigger, in the sense of either leading back to it and hence reinforcing its activation or ending up with another potential trigger that would shift the composition of the manifolds of possible action trajectories related with it (we throw the apple at our partner, but he just happily returns it, and we begin an 'apple play').

\section{The cultural constitution of agent identity}

The first conclusion from this brief analysis is that Darwinian evolution only takes place at the neuronal level, as a complex multi-level process involving various meta-representations, such as proprioceptions. The question then arises as to how these meta-levels ultimately refer to the external world. Here it is essential to recognize that all representations establish implicit relations to the external world by being tied to an action as the ultimate anchor. But how can we avoid Wittgenstein's private language fallacy? This was also recognized by Gerald Edelman (1987): He argued that the stabilizing force of the system is its 'intraspecies communication'. That is straightforward, since we only need to include one special kind of action, which is communication: Assume, for example, that in order to get the apple I must ask someone else to hand it over to me. In other words, action coordination is the framework that establishes the convergence and stability of internal representations within and between individuals. This idea establishes a direct conceptual bridge to biosemiotics since we can interpret this in terms of von Uexkuell's (1956) notion of evolved species-centred 'Umwelten': In Lotmanian terms, this amounts to species-centred semiospheres.

Hence, the complete picture (building on earlier speculations in Herrmann-Pillath 2010) is that we must minimally consider a dyad of interacting agents to establish why internal neuronal evolution results in a convergent semiosphere across agents (this matches with the emphasis on dialogue in Lotmanian semiotics, see Edwards 2015 and Gherlone 2016). Here, the semiosphere is the world as we experience it, which is anchored in the world as a physical fact via our actions. The semiosphere is also what the generic biological notion of 'culture' refers to: A universe of representations of the world, which is, in principle, autonomous, such that what constitutes 'reality' for us emerges in the semiosphere (basically, this corresponds to Dennett's 1995 account of internalizing natural selection via the construction of inner worlds). For example, we may sustain beliefs in magic, until the endogenous development of science motivates us to give up these beliefs: But science is just another manifestation of the semiosphere, governed by specific epistemic disciplines, most importantly, the rules of rational discourse (this view was fully elaborated by Cassirer 1923-29).

In Figure 4, what constitutes the world is the mirror (literally, mediated via mirror neurons and similar neuronal structures) between EA and EA', which relates to the convergent simulations of actions involving the external object, say, the apple. The convergence is only established via successful action 
coordination or successful communication over the action that crosses the physical boundary between the two bodies and brains. One important implication is that we cannot assume that there is also a convergence of neuromemetic structures, since what counts is the interplay of actions and hence the emergence of a shared semiosphere. This corresponds to the level of 'traits' in Darwinian theories of culture evolution. Therefore, there is a principled difference between genes and neuromemes: Neuromemes cannot be propagated via the somatic level between individuals.

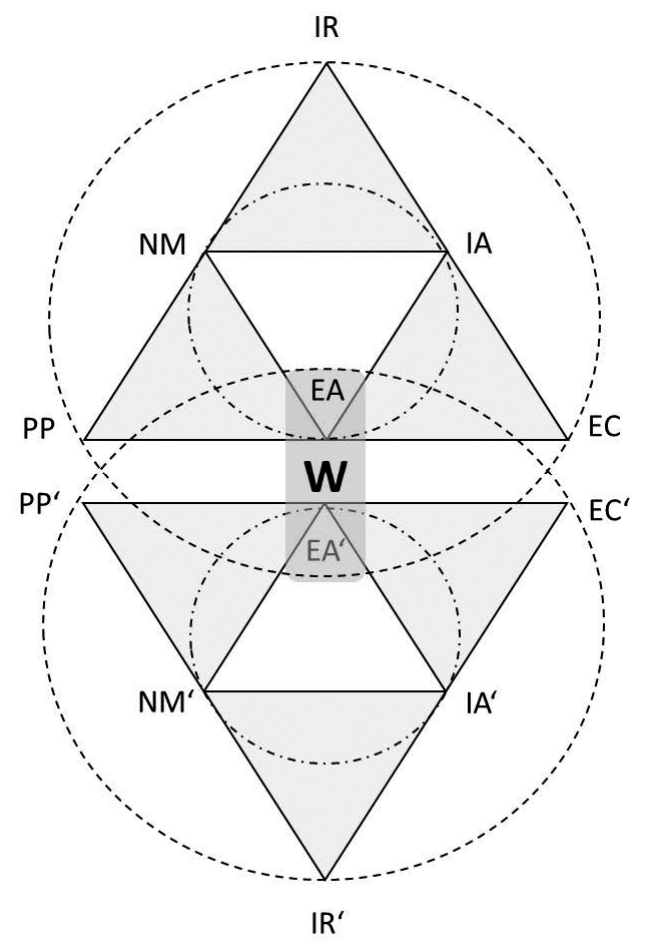

Figure 4. Interactive (dyadic) semiotic constitution of the world

However, as argued previously, I strongly object to equating the semiosphere with culture (this is a specific position in the debate, which differs from others' opinions, such as Torop 2005 arguing that the semiosphere is bivalent, both as an object-language and metalanguage). Culture is about the internal segmentation of the semiosphere and the construction of the agent that drives the action, and specifically about establishing, sustaining and expressing its identity. There is a deep evolutionary rationale for this: Humans depend on cooperation in groups for survival, and hence collective action coordination is an essential precondition. However, considering von Uexkuell's ideas, reinstated in recent zoosemiotics (Maran et al. 2016), we could envisage a non-anthropocentric concept of culture in terms of the diversity of species-specific semiospheres that define a diversity of 'worlds'. I think that this would still stretch the concept of culture.

Zawidski (2013) presented a convincing argument why 'mind-shaping' is a core human capacity, and why in this context the construction of identities is essential. There are many reasons for that, but I only present one here: Once actions are interactive with others, predicting the actions of others becomes a crucial requirement for successful coordination. However, the evolutionary dynamics of the hypercomplex human brain renders this extremely difficult, if not logically impossible, in a Gödelian twist. Therefore, humans have evolved the capacity for mind-shaping, which includes the motivation for subjecting oneself to mind-shaping activities, such as active imitation, the willingness to follow pedagogical orientations, or a penchant to conformity. All these various activities imply the sharing of internal representations in externalized media, such as artefacts, rituals or narratives deeply related 
to our identities as agents. This is what Hartley and Potts (2014) refer to as 'culture', and I agree, contra Mesoudi, but also contra Lotman, upon first sight.

Hence, as elaborated in Figure 4, the world $(\mathbf{W})$ as the transcendental reference point for actions in the semiosphere becomes fixated via the mutual convergence of individual semiospheres that are anchored in a shared field of action consequences related with proprioceptions and alteroceptions. It is a well-established result of developmental neuroscience that distinguishing between another's action and one's own action is an epistemic achievement, and that the fusion of both is the precondition for the specifically human capacities of imitation: Simulations of the action types may be indifferent to who actually acts (Hurley 2008). This view can be also accommodated with Lotmanian semiotics (for example, Gherlone 2016). Yet, for action coordination it is indispensable to distinguish between the identities of the different actors: This is the evolutionary achievement of culture, and refers to many levels, such as the individual, the dyad, the group or even large societies. Hartley and Potts (2014) refer to these by the generic term of 'demes'. The specific evolutionary function of culture is to create individual agents who are at the same time 'dividuals', in the sense of sharing semiospheres in distinction to 'the rest', which is the precondition for deme-level cooperation.

Obviously, the general neuromemetic analysis also applies to culture, which explains the pivotal role of what is today often treated colloquially as a 'meme', such as specific narratives, symbols, songs, whatever (Cannizarro 2016). These are objects of the semiosphere, and their stability is rooted in the neuromemetic feedback circuits, such as stories triggering certain emotional responses that eventually find root in affectually loaded sensorimotor simulations of actions. To take the apple again, accordingly the object 'apple' is semiotically mediated in a complex evolving flow of semiosis that establishes multifarious interpretations, such as referring to the biblical apple or the brand. Their core cultural dimension, however, is about reflecting the differences of action patterns across boundaries of demes as 'made by culture.' This is a major departure from Lotman, while also confirming his treatment of the border as the essential phenomenon of culture, especially when it comes to cultural creativity resulting from an interaction across borders.

In naturalistic terms, this is grounded in von Uexkuell's concept of 'Umwelt', which implies that the semiosphere is internally structured via borders: Indeed, the apple in the 'Umwelt' of human species is represented differently than in the 'Umwelt' of fruit flies. However, I suggest that we should refrain from extending even this notion of 'culture' to the biosphere or even beyond. Culture is about reflecting the border in specific human forms of semiosis, foremostly language, and therefore presupposes distinctly human capacities for reflection, which are manifest in the activity of translation, as much emphasized by Lotman. We cannot translate the semiotic construction of the apple by the fruit fly into human language, but we can translate different symbolic uses of 'apple' across human groups. In highlighting this difference, we can also build a bridge between the biosemiotic analysis of cultural evolution and the engagement of Lotmanian semiotics with the literature and the arts (Wheeler 2016).

\section{Conclusion}

We can now clearly assign the role of Darwinian analysis in understanding cultural evolution: This is the neuromemetic dynamics of the brain. Hence, we get a neat correspondence between the units of biological and cultural evolution in terms of the replicator notion: The gene and the neuromeme. Most of what is treated as a unit in common Darwinian approaches to cultural evolution is represented by phenotypical traits. We can now specify these as 'signs' in the semiosphere. We can also now employ all the analytical tools introduced by Mesoudi and others on the dynamics of the semiosphere, such as employing power laws for explaining why certain videos become viral on YouTube. But this does not mean that we engage in evolutionary theory sensu strictu: We only investigate certain mechanisms 
of diffusion, but not the fundamental processes of variation, selection and retention, which take place only at the neuromemetic level.

We can further clarify the concept of 'cultural information': This is the information enacted via the semiosis of self-reproducing neuromemes and which is essential for constituting and sustaining an agent's identity. This creates another correspondence between biological and cultural evolution. However, regarding biological evolution, we need to match certain fundamental assumptions about the two domains, in the sense that we need to focus on those variants of evolutionary theory that approach biological information as systemic phenomena and that reject genetic reductionism. These are those theories that highlight the role of development in activating genetic information (Oyama 2001), that emphasize the role of the niche in carrying biological information (Odling-Smee et al. 2003) and that deflate the role of genes to 'bookkeeping' devices in a complex multi-level systemic view of evolution (Gould 2002). In such a non-reductionist framework, it is a straightforward process to develop integrative evolutionary models that bridge biology and culture (seminally, Jablonka and Lamb 2006). These models are compatible with biosemiotic approaches to biological evolution (Kull 2000). Hence, the fusion of evolutionary theory and semiotics is possible; thus providing the theoretical foundation for cultural science. This is a pendulum-like analytical movement: Naturalizing semiotics implies that we can develop a concise notion of semantic information in biology; based on this, we can move back to culture. However, this does not mean that we Darwinize culture in terms of reducing culture to biological mechanisms, as has been championed in many evolutionary approaches to the arts, religion and so forth. We posit a fundamental duality of biological and cultural information, where the latter is grounded in the brain, thus decoupling culture from natural selection as operating on biological information.

Accordingly, the relevant disciplines for naturalistic semiotics in cultural sciences are the neurosciences. In the past decades, new fields have been emerging, such as social neuroscience (Ward 2017) and cultural neuroscience (Han et al. 2013) that highlight the interaction between external carriers of information and brain mechanisms, resulting in non-reductionist brain sciences, as championed by Northoff (2014). These approaches also offer new views on relating neurosciences and economics (Alós-Ferrer 2018; Harbecke and Herrmann-Pillath 2020), thus opening venues to combine the two threads of evolutionary cultural analysis and evolutionary economics.

\section{Acknowledgements}

I am grateful to two anonymous reviewers who suggested some important clarifications of my argument. Special thanks also to John Hartley and Winfried Nöth, who helped to fix potential confusions about Lotman's and Peirce's original ideas. Any remaining flaws are of my own making.

\section{References}

Alesina, A. and Paola Giuliano, P. 2015. Culture and institutions. Journal of Economic Literature 53(4): 898-944. DOl: doi.org/10.1257/jel.53.4.898.

Alós-Ferrer, C. 2018. A review essay on Social Neuroscience: Can research on the social brain and economics inform each other? Journal of Economic Literature 56 (1): 234-64. www.aeaweb.org/ articles?id=10.1257/jel.20171370

Andrews, E. 2015. The importance of Lotmanian semiotics to sign theory and the cognitive neurosciences. Sign Systems Studies 43(2/3): 347-64. DOI: doi.org/10.12697/SSS.2015.43.2-3.10 
Ariely, D. and Norton, MI. 2009. Conceptual consumption, Annual Review of Psychology, 60: 475-499. DOl: doi.org/10.1146/annurev.psych.60.110707.163536

Aunger, R. 2002. The electric Meme: A new theory of how we think. New York et al.: Free Press.

Aunger, R. (ed.). 2000. Darwinizing culture: The status of memetics as a science, Oxford: Oxford University Press.

Barsalou, LW. 2008. Grounded cognition. Annual Review of Psychology 59: 617-645. DOl: doi.org/10.1146/annurev.psych.59.103006.093639.

Beugelsdijk, S. and Maseland, R. 2010. Culture in economics. History, methodological reflections, and contemporary applications. Cambridge: Cambridge University Press.

Bogdan, RJ. 2010. Our own minds: sociocultural grounds for self-consciousness. Cambridge, Mass: MIT Press.

Bowles, S. and Gintis, H. 2011. A cooperative species: human reciprocity and its evolution. Princeton: Princeton University Press.

Boyd, R. and Richerson, PJ. 1985. Culture and the evolutionary process. Chicago and London: University of Chicago Press.

Brumann, C. 1999. Writing for culture: Why a successful concept should not be discarded. Current Anthropology 40, Supplement, S1-S28. DOI: doi.org/10.1086/200058

Calvin, WH. 1998. Competing for consciousness: A Darwinian mechanism as an appropriate level of explanation. Journal of Consciousness Studies 5(4): 389-404.

Cannizzaro, S. (2016): Internet memes as internet signs: A semiotic view of digital culture. Sign Systems Studies 44(4): 562-86. DOI: doi.org/10.12697/SSS.2016.44.4.05

Cassirer, E.1923-29. Philosophie der symbolischen Formen. Philosophische Bibliothek, Bd. 607-609. Hamburg: F. Meiner Verlag.

Cavalli-Sforza, LL. and Feldman MW. 1981. Cultural transmission and evolution. Princeton: Princeton University Press.

Cisek, P. 2007. Cortical mechanisms of action selection: The affordance competition hypothesis. Philosophical Transactions of the Royal Society B: Biological Sciences 362(1485): 1585-99. DOl: doi.org/10.1098/rstb.2007.2054

Daston, L. and Galison, P. 2010. Objectivity. New York, NY: Zone Books.

Dawkins, R. 1989. The selfish gene, new edition. Oxford and New York: Oxford University Press.

Deacon, TW. 2013. Incomplete nature: How mind emerged from matter. New York: Norton.

Dennett, DC. 1995. Darwin's dangerous idea: evolution and the meanings of life. New York: Simon \& Schuster.

Edelman, GM. 1987. Neural darwinism: The theory of neuronal group selection. New York: Basic Books.

El-Hani, CN.; Queiroz J. and Emmeche, C. 2006. A semiotic analysis of the genetic information system. Semiotica 160 : 1-68. DOl: doi.org/10.1515/SEM.2006.039

Fernando, C.; Szathmáry, E. and Husbands, P. 2012. Selectionist and evolutionary approaches to brain function: A critical appraisal. Frontiers in Computational Neuroscience 6. DOI: doi. org/10.3389/fncom.2012.00024

Floridi, L. 2019. Semantic conceptions of information, The Stanford Encyclopedia of Philosophy (Winter 2019 Edition), Edward N. Zalta (ed.), plato.stanford.edu/archives/win2019/entries/information-semantic/.

Friston, K. 2010. The free-energy principle: A unified brain theory. Nature Reviews Neuroscience, DOI: doi.org/10.1038/nrn2787.

Geertz, C. 1973. The interpretation of cultures: Selected essays. London: Fontana Press.

Gherlone, L. 2016. Vygotsky, Bakhtin, Lotman: Towards a theory of communication in the horizon of the other. Semiotica 213: 75-90. DOI: doi.org/10.1515/sem-2015-0031. 
Godfrey-Smith, P. and Sterelny, K. 2016. Biological information. The Stanford Encyclopedia of Philosophy (Summer 2016 Edition), Edward N. Zalta (ed.), plato.stanford.edu/archives/sum2016/ entries/information-biological/.

Gould, SJ. 2002. The structure of evolutionary theory. Cambridge, MA, USA and London: Belknap.

Hadders-Algra, M. 2018. Early human motor development: From variation to the ability to vary and adapt. Neuroscience \& Biobehavioral Reviews 90: 411-27. DOl: doi.org/10.1016/j.neubiorev.2018.05.009.

Han, S.; Northoff, G.; Vogeley, K.; Wexler, B. E.; Kitayama, S. and Varnum, MEW. 2013. A cultural neuroscience approach to the biosocial nature of the human brain. Annual Review of Psychology 64, 335-59. DOl: doi.org/10.1146/annurev-psych-071112-054629.

Harbecke, J. and Herrmann-Pillath, C. (eds). 2020). Social neuroeconomics: mechanistic integration of the neurosciences and the social sciences. London: Routledge.

Hartley, J. 2003. A short history of cultural studies. London: Sage.

Hartley, J. and Potts. J. 2014. Cultural science: a natural history of stories, demes, knowledge and innovation. London, New York: Bloomsbury Academic.

Hartley, J. 2021. Advanced introduction to creative industries. Cheltenham: Edward Elgar.

Hartley, J.; Ibrus, I. and Ojamaa, M. 2020. On the digital semiosphere: culture, media and science for the anthropocene. New York: Bloomsbury Academic.

Hayek, F. A. von. 1952. The sensory order. An inquiry into the foundations of theoretical psychology. Chicago: University of Chicago Press.

Herrmann-Pillath, C. 2010. The economics of identity and creativity. A cultural science approach. St. Lucia: University of Queensland Press and New Jersey: Transactions.

Herrmann-Pillath, C. 2012. Towards an externalist neuroeconomics: dual selves, signs, and choice. Journal of Neuroscience, Psychology and Economics 5(1): 38-61. DOI: doi.org/10.1037/a0026882.

Herrmann-Pillath, C. 2013. Foundations of economic evolution: A treatise on the natural philosophy of economics. Cheltenham: Edward Elgar.

Herrmann-Pillath, C. 2017. China's economic culture: The ritual order of state and markets. Abingdon and New York: Routledge.

Herrmann-Pillath, C. 2018. Beyond dualities in behavioural economics: what can G. H. Mead's conceptions of self and reflexivity contribute to the current debate? Journal of Economic Methodology 26(2): 118-132. DOl: doi.org/10.1080/1350178X.2018.1501081.

Herrmann-Pillath, C. 2020. Mechanistic integration of social sciences and neurosciences: Context and causality in social neuroeconomics, in: Harbecke, J. and Herrmann-Pillath, C. (eds.). Social neuroeconomics: Mechanistic integration of the neurosciences and the social sciences, Abingdon and New York: Routledge, pp. 47-73.

Herrmann-Pillath, C. 2021a. The natural philosophy of economic information: Autonomous agents and physiosemiosis. Entropy 23, 277. DOl: doi.org/10.3390/e23030277.

Herrmann-Pillath, C. 2021 b. Evolutionary mechanisms of choice: Hayekian perspectives on neurophilosophical foundations of neuroeconomics. Economics and Philosophy 37: 284-303. DOl: doi.org/10.1017/S0266267120000371.

Herrmann-Pillath, C. and Salthe, SN. 2011. Triadic conceptual Structure of the maximum entropy approach to evolution. BioSystems 103: 315-330. DOI: doi.org/10.1016/j.biosystems.2010.10.014

Hoffmeyer, J. 1996. Signs of meaning in the universe. Bloomington: Indiana University Press.

Hommel, B. and Wiers, RW. 2017. Towards a unitary approach to human action control. Trends in Cognitive Sciences 21(12): 940-49. DOI: doi.org/10.1016/j.tics.2017.09.009

Hull, DL.; Langman, RE. and Glenn, SS. 2001. A general account of selection: biology, immunology and behaviour. Behavioral and Brain Sciences 24(2): 511-573. DOI: doi.org/10.1017/ S0140525X01004162. 
Hulswit, M. 2002. From cause to causation: a Peircean perspective. Dordrecht: Kluwer Academic Publishers.

Hurley, S. 2008. The shared circuits model: How control, mirroring and simulation can enable imitation, deliberation, and mindreading. Behavioral and the Brain Sciences, 31 (1): 1-21. DOI: doi.org/10.1017/S0140525X07003123.

Jablonka, E. and Lamb, MJ. 2006. Evolution in four dimensions: Genetic, epigenetic, behavioral and symbolic variation in the history of life. Cambridge, MA, USA and London: MIT Press.

Kolchinsky, A. and Wolpert, DH. 2018. Semantic information, autonomous agency and nonequilibrium statistical physics. Interface Focus 8(6). 20180041. doi.org/10.1098/rsfs.2018.0041.

Kull, K. 2000. Copy versus translate, meme versus sign: development of biological textuality, European Journal for Semiotic Studies 12(1): 101-120.

Lashley, K. S. 1951. The problem of serial order in behavior. In: L. A. Jeffress (ed.), Cerebral mechanisms in behavior. New York: Wiley, pp. 112-146.

Levine, J. 2009. The explanatory gap. In: McLaughlin, B. P., Beckermann, A. and Walter, S. (eds.), The Oxford Handbook of Philosophy of Mind, Oxford: Clarendon Press, pp. 281-291.

Lotman, Y. 1990. Universe of the mind: A semiotic theory of culture. Bloomington \& Indianapolis: University of Indiana Press.

Macdonald, G. and Papineau, D. 2006. Introduction: Prospects and problems for teleosemantics. In Macdonald, G. and Papineau, D. (eds.), Teleosemantics: New philosophical essays. Oxford and New York: Oxford University Press, pp. 1-22.

Maran, T.; Tonessen, M.; Tüür, K.; Magnus, R.; Ratasepp, S. and Mäekevi, N. 2016. Methodology of Zoosemiotics: Concepts, Categorisations, Models. In Maran, T. et al. (eds.). Animal Umwelten in a Changing World: Zoosemiotic Perspectives. Tartu: University of Tartu Press.

Maturana, HR. and Varela, FJ. 1980. Autopoiesis and cognition: the realization of the living. Dordrecht and Boston: D. Reidel.

Maynard Smith, J. 2000. The concept of information in biology. Philosophy of Science 67(2): 177-194. DOl: doi.org/10.1086/392768.

McDowell, JJ. 2019. On the current status of the evolutionary theory of behavior dynamics. Journal of the Experimental Analysis of Behavior 111(1): 130-45. DOl: doi.org/10.1002/jeab.495.

Mead, GH. 1932 (2015). Mind, self, and society. The definitive edition. Chicago, London: University of Chicago Press.

Mesoudi, A. 2011. Cultural evolution: how Darwinian theory can explain human culture and synthesize the social sciences. Chicago and London: University of Chicago Press.

Metcalfe, JS. 1998. Evolutionary economics and creative destruction. London and New York: Routledge.

Millikan, RG. 2009. Biosemantics. In: McLaughlin, B. P., Beckermann, A. and Walter, S. (eds.), The Oxford Handbook of Philosophy of Mind, Oxford: Clarendon Press, pp. 394-406.

Neander, K. 2006. Content for cognitive science. In Macdonald, G. and Papineau, D. (eds.), Teleosemantics: New philosophical essays. Oxford and New York: Oxford University Press, pp. 167-194. Nelson, RR. and Winter, SG. 1982. An evolutionary theory of economic change. Cambridge, MA, USA and London: Belknap.

Nöth, W. 2001. Protosemiotics and Physicosemiotics. Sign System Studies 29(1), 13-26.

Nöth, W. 2002. Charles S. Peirce's theory of information: A theory of the growth of symbols and of knowledge. Cybernetics \& Human Knowing, 19(1-2): 137-161.

Northoff, G. 2014. Minding the brain? Introduction to non-reductive neurophilosophy. New York: Palgrave Macmillan.

Northoff, G. 2016. Cultural neuroscience and neurophilosophy: Does the neural code allow for the brain's enculturation? In Chiao, J. Y., Li, S.-C., Seligman, R. and Turner, R. (eds.), The Oxford 
Handbook of Cultural Neuroscience, Oxford and New York: Oxford University Press. pp. 21-40.

Odling-Smee, FJ.; Laland, KN. and Feldman, MW. 2003. Niche construction: The neglected process in evolution. Princeton: Princeton University Press.

Oyama, S. 2001. The ontogeny of information: Developmental systems and evolution. Durham and London: Duke University Press.

Papineau, D. 2009. The Causal Closure of the Physical and Naturalism. In: McLaughlin, B. P., Beckermann, A. and Walter, S. (eds.), The Oxford Handbook of Philosophy of Mind, Oxford: Clarendon Press, pp. 53-65.

Pezzulo, G. and Cisek, P. 2016. Navigating the affordance landscape: Feedback control as a process model of behavior and cognition. Trends in Cognitive Sciences 20(6): 414-24. DOl: doi.org/10.1016/j.tics.2016.03.013.

Piaget, J. 1975. L'Équilibration des structures cognitives: problème central du développement, Paris: Presses Universitaires de France.

Rogers, DS. and Ehrlich, PR. 2008. Natural selection and cultural rates of change. Proceedings of the National Academy of Sciences 105(9), 3416-3420. DOI: doi.org/10.1073/pnas.0711802105.

Ross, D. 2007. H. sapiens as ecologically special: What does language contribute? Language Studies 29, 710-731. DOl: doi.org/10.1016/j.langsci.2006.12.008.

Queiroz, J.; Emmeche, C. and El-Hani, CN. 2008. A Peircean approach to 'information' and its relationship with Bateson's and Jablonka's ideas, The American Journal of Semiotics 24.1-3: 75-94

Salthe, Stanley N. 2009. The system of interpretance: Meaning as finality. Biosemiotics 1, 285-294.

Schlaile, MP. 2021. Memetics and evolutionary economics: To boldly go where no meme has gone before. Cham: Springer Nature Palgrave Macmillan, DOl: doi.org/10.1007/978-3-030-59955-3.

Short, TL. 2007. Peirce's theory of signs. Cambridge, UK and New York: Cambridge University Press.

Tamm, M. (ed.) 2019. Juri Lotman - Culture, memory and history: essays in cultural semiotics. Cham: Springer Nature Palgrave Macmillan.

Torop, Peeter 2005. Semiosphere and/as the research object of semiotics of culture. Sign Systems Studies 33(1): 159-73.

Uexkuell, J. von and Kriszat, G. 1956. Streifzüge durch die Umwelten von Tieren und Menschen. Bedeutungslehre. Rowohlt: Hamburg.

Vygotsky, LS. 1934 (2012): Thought and Language. Rev. and Expanded ed. Cambridge, Mass: MIT Press.

Ward, J. 2017. The student's guide to social neuroscience. Second Edition. London, New York: Routledge.

Wheeler, W. 2016. Expecting the earth: life, culture, biosemiotics. London: Lawrence \& Wishart.

Zawidzki, T. 2013. Mindshaping: a new framework for understanding human social cognition. Cambridge, Mass: MIT Press.

\section{Author information}

Carsten Herrmann-Pillath is Professor and Permanent Fellow at the Max Weber Centre for Advanced Cultural and Social Studies, University of Erfurt, German. His major fields of research are economics and philosophy, institutional change and economic development, ecological economics and Chinese economic studies. His publications include 500+ academic papers and 20 books, covering a broad cross-disciplinary range in economics, the humanities and the sciences. Personal Website: cahepil.net. Blog: technosphere.blog. 
CULTURAL SCIENCE JOURNAL 13(1), 2021

Carsten Herrmann-Pillath

○

OPEN ACCESS

Copyright: @ 2021 The Author(s). This is an open-access article distributed under the terms of the CreativeCommons Attribution 4.0 International License (CC-BY 4.0), which permits unrestricted use, distribution, andreproduction in any medium, provided the original author and source are credited. See http://creativecommons.org/licenses/by/4.0/.

Cultural Science Journal is a peer-reviewed open access journal published by Tallinn University and Sciendo. 